\title{
Relações entre Economia e Marketing
}

O presente artigo tem como objetivo discutir os elementos econômicos e as decisões de marketing. O referencial teórico busca apresentar como os fatores são relevantes e como os agentes econômicos que são também públicos das ações de marketing atuam. Essa definição mostra quais são esses elementos e como se relacionam entre as disciplinas, apresentando então a relevância do entendimento das duas áreas para certas decisões. A metodologia aborda o tema de forma qualitativa para dar uma visão teórica sobre o assunto. Ao final do artigo após as discussões acerca da teoria pode-se entender que a relação entre os elementos da economia e as decisões de marketing estão interligados sem poder se definir na maior parte dos momentos qual está tendo maior influência sobre o outro.

Palavras-chave: Economia; Consumidor; Marketing.

\section{Relations between Economy and Marketing}

This article aims to discuss economic elements and marketing decisions. The theoretical framework seeks to present how the factors are relevant and how the economic agents that are also public of the marketing actions act. This definition shows what these elements are and how they relate to the disciplines, thus presenting the relevance of the understanding of the two areas for certain decisions. The methodology approaches the subject in a qualitative way to give a theoretical view on the subject. At the end of the article after the discussions about the theory one can understand that the relationship between the elements of the economy and the marketing decisions are interconnected without being able to define in most of the moments which is having greater influence on the other.

Keywords: Economy; Consumer; Marketing.

Topic: Marketing e Estratégias Mercadológicas

Reviewed anonymously in the process of blind peer.

Camila de Souza Alves

Universidade Federal de Minas Gerais, Brasil

http://lattes.cnpq.br/1806005813321390

camiladsa@live.com
Received: 10/01/2017

Approved: 11/03/2017
Referencing this:

ALVES, C. S.. Relações entre Economia e Marketing. Revista Brasileira de Administração Científica, v.8, n.1, p.64-71, 2017. DOI: http://doi.org/10.6008/SPC2179-684X.2017.001.0005

DOI: 10.6008/SPC2179-684X.2017.001.0005 


\section{INTRODUÇÃO}

A economia é uma ciência de análise quantitativa e qualitativa. Os fatos podem ser explicados por meios de textos, gráficos, cálculos e consideram diversos fatores para chegar às conclusões que serão apresentadas. Servindo como guia para decisões governamentais e também pessoais, a economia está diariamente inserida na vida das pessoas em decisões simples ou complexas, os fatores econômicos estão presentes em quase todos os dilemas que precisam de uma solução.

O marketing pode se relacionar a pessoas físicas ou jurídicas, e é de maneira geral definido como um intermédio entre empresa e consumidor, mas essa definição é restritiva, afinal o marketing não é simplesmente um meio de conquistar o cliente. Além disso, e do que na maioria das vezes se imagina, o marketing atua em grande parte dos processos econômicos e sociais, não só na relação empresa e cliente, mas também nas relações com fornecedores, pontos de venda e com os próprios trabalhadores.

É do conhecimento de todos que ao longo do tempo a sociedade passou por diversas mudanças em todos os sentidos, na economia essas alterações levaram a aumentos de produtividade e concorrência, além de estreitar sua relação com as demais áreas. O número de produtos e serviços oferecidos e as formas de oferta e demanda estão cada vez maiores, tem-se várias escolhas.

Não se decide apenas que produto comprar, a escolha envolve as várias marcas existentes, as diversas formas de pagamento, a possibilidade de comprar na loja ou pela internet, essas opções levam a necessidade latente de se diferenciar para ter a preferência e isso leva ao marketing, que utilizará diversas ferramentas, entre elas a própria economia. A relação se torna ainda mais clara quando se analisam fatores de comunicação, como a publicidade ou a propaganda, que são meios de relação entre o ofertante de determinado produto ou serviço e o seu público-alvo, e de acordo com Lage et al. (1994), a propaganda está à disposição da sociedade industrial moderna e contribui então com os setores econômicos.

Quais são as relações entre os elementos da economia e as decisões de marketing? Não se é ignorada a relação entre as disciplinas, mas seu estudo em conjunto é deixado de lado e tido como algo que acontecerá naturalmente, isso pode ocasionar um déficit de conhecimento e levar a uma análise superficial quando essa se fizer necessária, entender as relações entre economia e marketing não significa apenas saber que são assuntos dependentes um do outro, é necessário que se conheçam os pontos e os níveis dessa dependência e o que pode ser feito para que ambas coexistam cooperando para que as duas alcancem os objetivos desejados.

As decisões dos agentes envolvidos serão influenciadas direta ou indiretamente por diversos fatores, e os próprios envolvidos são fatores nas questões econômicas e de marketing, assim podemos definir as pessoas como agentes em termos econômicos e públicos em termos de comunicação, tem-se por objetivo enumerar e discutir os fatores da economia que causam a necessidade de se ter certas estratégias no marketing e como isso pode levar a alterações na economia.

A divisão do artigo se dá por seções. A seção seguinte apresenta a teoria utilizada para analisar as relações entre as disciplinas analisadas. Subsequentemente, tem-se a metodologia usada para o 
desenvolvimento do trabalho. Consecutivamente, a discussão acerca do tema de acordo com o que foi visto no referencial teórico; por fim, as conclusões que podem ser obtidas após a análise do artigo.

\section{REVISÃO TEÓRICA}

\section{Oferta e Demanda}

A demanda é a quantidade de um bem que os consumidores querem e podem adquirir enquanto a oferta é a quantidade que os vendedores querem e podem vender. Por isso as preocupações dos economistas não dizem respeito apenas ao que as pessoas desejam comprar, mas também e principalmente com o que elas efetivamente compram (STIGLITZ et al., 2003).

Segundo Mankiw (2005), as leis de demanda e oferta definirão suas relações com as alterações do preço, tudo o mais mantido constante a demanda diminui e a oferta aumenta se houver um aumento do preço. As alterações podem causar excesso de demanda ou oferta e por isso os dois fatores são analisados em conjunto para que se conheça o ponto de equilíbrio e se possam buscar meios de mantê-lo.

Na determinação dos fatores econômicos que devem ser usados como aliados pelo marketing temos a visão de Dias (2003) que aponta o conhecimento sobre oferta e demanda como fundamental tanto no setor de atuação da empresa quanto nos setores que sejam seus complementares. O marketing tem a função de auxiliar na manutenção da relação entre oferta e demanda quando essa está satisfatória ou de buscar formas de alterar a situação quando houver algum problema que leve a empresa a ter um desequilíbrio em seus resultados.

A definição de Kotler (1999) é que o sucesso em termos financeiros em muitos casos é dependente do marketing pois a produção não terá nexo se não houver demanda de mercado pelo produto e pelos serviços já que é isso que ocasiona o lucro. O marketing identifica necessidades e altera configurações para alcançar um melhor resultado, as ferramentas de marketing podem auxiliar a neutralizar efeitos que descontrolam a economia, segundo Cobra (1993), é inegável o papel do marketing no estímulo a demanda.

\section{Mercado, Venda e Consumo}

Segundo Oliveira (1993) “mercados são pessoas físicas ou jurídicas que vendem e compram bens ou serviços", entretanto não basta se conhecer a definição do que é mercado, deve-se saber qual é o mercado. O desejo de quem oferta o produto é vendê-lo, mas para alcançar esse objetivo deve-se conhecer quem irá demandá-lo. Em Mankiw (2005) encontramos a definição para a relação entre produtores e consumidores no mercado como sendo uma busca individual por bem-estar que culmina em um equilíbrio capaz de satisfazer a necessidade de ambos os lados envolvidos.

Kotler (1999) afirma que "nenhuma empresa em sã consciência tenta vender para qualquer pessoa", para isso a necessidade latente é que se definam os mercados-alvo de cada empresa, em que mercado cada produto trará o rendimento desejado para a empresa, qual mercado está pronto para receber a oferta que se deseja disponibilizar para os consumidores. 
Visando a facilitação das definições os mercados podem ser segmentados, no que diz respeito a área socioeconômica os segmentos serão identificados de acordo com classe social, nível de renda, grau de escolaridade, ocupação profissional e posse de bens. A segmentação pode ou não levar a empresa a adotar diferentes formas de comercializar e divulgar seus produtos para alcançar maior eficácia. $\mathrm{O}$ marketing deve se aliar a economia na quantificação de mercado, que consiste em definir objetivos seja de venda ou de participação no mercado em questão, isso é essencial para o desempenho da empresa e para a análise dos resultados obtidos (DIAS, 2003). Dias (2003) afirma que:

O homem deve ser moldado para fazer marketing, para integrar as suas ações de marketing, para integrar às suas ações de vendas um papel generalista, de um gerente de território, que venda, cobre, negocie, faça promoção, pesquise, identifique necessidades, saiba prestar bons serviços ao seu cliente e, sobretudo, esteja preparado para propor alternativas de soluções a cada problema cotidiano do seu cliente. (DIAS, 2006)

As mudanças na produtividade e nos setores de comunicação levaram a uma mudança na forma de vender, não se vende apenas e simplesmente pelo lucro, mas sim pela necessidade de manutenção do equilíbrio. Toda essa nova configuração econômica e a utilização do marketing levam a necessidade de se iniciar o trabalho de venda dentro da própria empresa. Segundo Kotler et al. (2007), o sucesso do marketing depende do relacionamento com os diversos departamentos da empresa que devem agir pensando no consumidor para construir o valor da empresa

Para Stiglitz et al. (2003), para medir a utilidade de um produto e quanto o consumidor o deseja deve ser perguntado o quanto estaria disposto a pagar por uma coisa em relação a outra. O consumidor tem uma quantia máxima que está disposto a pagar por um bem de acordo com Mankiw (2005), mas nem sempre é essa a quantia que ele paga pelo bem já que o ofertante não conhece essa informação quando define o seu preço.

Constata-se, em Kotler et al. (2007), que a intenção de compra e a decisão de compra do consumidor nem sempre são as mesmas, ele pode ser influenciado por diversos fatores entre esses fatores estão os aspectos culturais, sociais, pessoais e psicológicos. $\mathrm{O}$ aspecto econômico está contido nos fatores pessoais e o marketing nos fatores psicológicos de motivação.

\section{Publicidade, Propaganda e Inovações Tecnológicas}

O pressuposto da publicidade é de que a atitude do público-alvo pode ser influenciada em relação ao consumo e para isso existem vários meios de se chegar ao consumidor, muitos anúncios levam o produto para a base afetiva das atitudes, o associam com emoções e valores. $O$ anunciante busca a associação do seu produto com sentimentos de boa vontade em termos gerais (ARONSON et al., 2002).

Para Cobra (1993) "o desenvolvimento paralelo da propaganda e dos meios de comunicação de massa é fruto do desenvolvimento econômico e da revolução industrial". Levando isso em consideração, tem-se a definição de Lage et al. (1994) de que o termo propaganda surgiu junto com o crescimento da produção e a sua diversificação, o termo foi criado quando o produtor das mercadorias ofertadas percebeu que precisava de uma forma para divulgar seu produto e diferenciá-lo dos demais, os meios de divulgação sempre existiram, mais tal qual são conhecidos hoje são o resultado da evolução. 
Para Stiglitz et al. (2003), o aumento no padrão de vida e na produtividade dos trabalhadores tem como base a mudança tecnológica, essa inovação se deve a alocação de verbas para pesquisas que permitem o desenvolvimento dessa área, em geral esses investimentos irão gerar externalidades positivas para os consumidores e para o mercado em geral.

A inovação tecnológica não seria possível sem a aceitação dela como um dos fatores determinantes para o desenvolvimento econômico e social, para Souza (2005) novas teorias consideram o progresso técnico como elemento ativo do processo de crescimento por ele levar a expansões do produto e aumentar a produtividade dos fatores de produção.

\section{METODOLOGIA}

Sendo considerada um procedimento formal, a pesquisa é um caminho para se conhecer a verdade segundo Lakatos et al. (1995). Não se trata, porém, de descobrir uma verdade para uma pergunta préestabelecida, mas sim de percorrer um caminho nessa busca que leve a teorias que tracem a verdade, para isso faz-se uso da pesquisa qualitativa para que ocorra um aprofundamento no contexto e então se faça uma interpretação condizente com a realidade. Para Severino (2002), o raciocínio é um processo que parte dos conhecimentos adquiridos para que se atinjam novos conhecimentos que possuam a mesma validade que os anteriores. A intenção da pesquisa qualitativa é essa, buscar a verdade partindo de um princípio já conhecido.

Opta-se pela utilização da pesquisa bibliográfica por esta permitir a discussão de um amplo número de fatos que podem estar envolvidos no tema da pesquisa. Seu desenvolvimento tem por base a utilização de material já existente que proporciona análises teóricas com várias visões do que se é tratado, é necessário cuidado para evitar problemas ocasionados pela distorção que pode ocorrer na visão de determinado autor; então, faz-se uso de várias fontes para evitar esse problema (GIL, 2002).

Para apresentar de forma clara o desenvolvimento foi utilizado o método indutivo, visando mostrar a conexão ascendente visto que os fatos caminham para planos cada vez maiores de relação entre si. A abordagem interpretativa utilizada possibilita explorar os fatores analisados levando em consideração fatos que seriam deixados de lado se fosse escolhida outra abordagem.

\section{RESULTADOS E DISCUSSÃO}

A relação entre economia e marketing é clara, ambas as áreas têm grande influência nas decisões das pessoas, seja nos termos pessoais ou profissionais. Cabe então aos profissionais das duas áreas agir para que elas sejam utilizadas em conjunto da maneira mais eficiente possível, ambas devem se auxiliar para garantir o bom andamento de empresas e mercados, já que atuam diretamente com isso. Não há como definir escalas de dependência entre elas, mas sim fatores em comum que levam a necessidade da outra, ou que apenas são divididos pelo lado econômico e pelo lado de marketing da situação em questão

A oferta e a demanda de produtos estão vulneráveis a várias influências, como produtos concorrentes, renda, preço, isso faz com que seja necessária a utilização de uma ferramenta capaz de 
controlar os problemas quando esses fatores estiverem em desequilíbrio e nada puder ser feito em termos econômicos, uma das opções então é adotar o marketing na busca de soluções alternativas que não tenham necessariamente que atuar mudando o cenário econômico e sim trabalhando de acordo com o estado em que ele se encontra.

Sabe-se que a grande busca das empresas com a oferta de produtos ou serviços é conseguir que as receitas obtidas sejam suficientes para Ihes trazer lucro, sendo assim o marketing atua auxiliando seja com o público consumidor ou com os diversos públicos envolvidos na produção, como fornecedores e funcionários.

A visão que o consumidor terá do produto está intimamente ligada a como o produto será ofertado. Por isso as empresas devem conhecer quem irá consumir seus produtos e analisar fatores como quais são os resultados esperados e quais as limitações para a demanda. Aliado ao conhecimento que se deve ter do público-alvo existe a necessidade de se conhecer em que mercado o produto deve ser inserido para alcançálo, afinal a intenção do produtor é vender, mas de nada adianta ele ter uma boa quantidade de produtos para ofertar e uma estratégia de marketing que garanta uma boa divulgação se o produto não estiver disponível para quem pretende demandá-lo.

Para essa situação a segmentação e a quantificação do mercado são importantes aliados, para se definir aonde ofertar e quanto ofertar, assim a empresa pode distribuir de maneira adequada seus produtos e maximizar o lucro, com isso ocorre também à maximização da satisfação do consumidor que consegue suprir suas necessidades. Para a perfeita harmonia entre a empresa e o mercado consumidor, o trabalho de endomarketing é essencial, dentro da própria empresa deve-se trabalhar pensando no consumidor em todos os pontos da produção, assim a criação do valor da empresa perante o público-alvo é muito mais eficaz do que quando o marketing é utilizado apenas quando o produto já está pronto e só o que falta é o consumidor comprá-lo.

O consumidor possui preferências, mas também está sujeito a restrições, essas podem ser de seu conhecimento já ou resultarem de situações inesperadas, isso explica as mudanças no comportamento do consumo. Ter a intenção de comprar um produto não significa que o consumidor irá de fato realizar a compra, afinal ele está sujeito a alterações em suas necessidades ou em sua situação financeira. Definir os fatores que levam o público-alvo a realmente comprar um produto é essencial para se decidir como ele será levado ao conhecimento das pessoas, não deixando de salientar que neste momento o mercado consumidor já foi previamente analisado em termos gerais, e então deve-se partir para uma análise especifica do público que se deseja alcançar, como hábitos de compra ou fatores que o levam a determinada decisão ou que podem alterar suas intenções.

Quando se diz respeito à divulgação do produto o marketing tem como principais aliadas a publicidade e a propaganda. Utilizando-se de vários meios de comunicação e de diversas formas de atingir o consumidor, a publicidade e a propaganda têm sua importância cada vez mais aceita, embora ainda sofram certa relutância de profissionais de outras áreas que as veem simplesmente como um meio de divulgar o preço do produto. Muito além disso são meios de se chegar ao público-alvo, de informá-lo sobre a empresa 
e o produto, de fazer com que a oferta aumente ou fique estável mesmo com o aumento do número de produtos concorrentes ou com crises que afetem diretamente a renda disponível para consumo. A cada dia as pessoas são atingidas por um número maior de informação e então a busca por diferenciação pode garantir a estabilidade e o equilíbrio financeiro na relação empresa consumidor, se determinado produto tem tradição e por isso deixa de investir na sua relação com o consumidor, é certo que este perderá mercado para produtos menos conhecidos mas que estão na busca de ampliação da sua participação no mercado.

A interligação de todos os setores é cada vez mais aparente, e o ponto crucial para que isso se tornasse uma realidade foi à inovação tecnológica, que no assunto em questão tem participação em dois diferentes momentos: no aumento da produtividade devido ao avanço dos meios de produção advindo das inovações tecnológicas e na facilidade cada vez maior de se propagar informações pelo mundo, o que possibilita diferentes meios de venda e divulgação de produtos.

As teorias econômicas tiveram que se adaptar a essas mudanças e introduzir em seus estudos o progresso técnico, já que a evolução dos processos de produção permitiu um aumento da produtividade, o mesmo trabalhador produz mais com o mesmo tempo quando há a chegada de uma nova tecnologia que permite por vezes que se faça em segundos o que seria feito em horas se não houvesse essa busca incessante por melhorias.

Para o marketing essas inovações trouxeram uma ampla gama de benefícios, desde a facilidade para se pesquisar sobre o mercado consumidor até a simplificação de como se chegar a ele, não é mais necessário usar apenas os meios comuns de divulgação, como rádio, revistas, jornais, a cada dia surge um novo jeito de divulgar o produto para o cliente e também de como fazer o produto chegar até ele, afinal é crescente o número de pessoas que adere as compras através da internet, o que leva a um novo tipo de mercado consumidor, que necessita de uma nova visão das empresas.

\section{CONSIDERAÇÕES FINAIS}

Definir níveis de relação entre elementos teóricos é uma difícil tarefa, que em alguns casos não deve ser feito devido ao risco de apresentar uma falsa impressão sobre o tema abordado. Na relação entre os elementos da economia e as decisões do marketing, fica aparente que os dois atuam lado a lado, com um grande número de fatores em comum e sem a possibilidade na maioria dos momentos de se definir qual área está exercendo influência sobre a outra. Estudos futuros podem utilizar dados que comprovem quantitativamente a relação entre a economia e o marketing, analisando qual o retorno dos investimentos econômicos na área de marketing, em que setores esse investimento é maior, e também com análises que enfoquem a opinião e a situação do consumidor baseando-se nos seus hábitos de consumo.

Um dos grandes fatores na relação é perceber que as decisões dos agentes estarão sempre ligadas a fatores ou acontecimentos que dependem de outros agentes ou de outras relações entre as áreas. Uma decisão na economia pode afetar uma decisão do consumidor, e isso altera a atitude que o marketing deve tomar, assim como uma atitude do consumidor altera a economia e gera diferentes necessidades do uso do 
marketing. Isso deixa claro que a relação está presente a todo momento e em todas as esferas, seja no setor econômico ou nas ações e estratégias de marketing.

\section{REFERÊNCIAS}

ARONSON, E.; WILSON, T. D.; AKERT, R. M.. Psicologia Social. 3 ed. Rio de Janeiro: LTC, 2002.

COBRA, M.. Marketing competitivo. São Paulo: Atlas, 1993.

DIAS, S. R.. Gestão de marketing. São Paulo: Saraiva, 2003.

KOTLER, P.. Marketing para o século XXI: como criar, conquistar e dominar mercados. 4 ed. São Paulo: Futura, 1999.

KOTLER, P.; ARMSTRONG, G.. Princípios de Marketing. 12 ed. São Paulo: Pearson Prentice Hall, 2007.

LAGE, B.; MILONE, P.. Propaganda e economia para todos. São Paulo: Summus, 1994.

LAKATOS, E. M.; MARCONI, M. A.. Metodologia do trabalho científico: procedimentos básicos, pesquisa bibliográfica, projeto e relatório, publicações e trabalhos científicos. 4 ed. São Paulo: Atlas, 1992.

MANKIW, N. G.. Introdução à economia. 3 ed. São Paulo: Thomson, 2005.

OLIVEIRA, P. S.. Introdução à economia. São Paulo: Ática, 1993.

SEVERINO, A. J.. Metodologia do trabalho científico. 22 ed. São Paulo: Cortez, 2002.

SOUZA, N. J.. Desenvolvimento econômico. 5 ed. São Paulo: Atlas, 2005.

STIGLITZ, J. E.; WALSH, C. E.. Introdução à microeconomia. 3 ed. Rio de Janeiro: Campus, 2003. 